\title{
Major macroeconomic disturbances, expectations and policy responses
}

\section{Daniel Heymann}

ECLAC Buenos Aires Office

dheymann@cepal.org.ar
The episodes of great financial volatility and wide fluctuations in the level of activity of a number of economies have heightened the debate on how major macroeconomic fluctuations are generated and spread. Although it is acknowledged that much can be learned from the study of specific cases, in the literature decisions are often presented as though the agents adopting them were fully aware of all the relevant probability distributions. It is desirable, however, that in analysing these phenomena it should be recognized that both the economic agents and policy-makers are acting in variable contexts, with perceptions and expectations that change according to the inferences that each one draws from the evolution of the surrounding environment. In these conditions, the interpretation of fundamental variables such as the fiscal deficit or the current account balance is necessarily conditioned by conjectures about their future evolution: it cannot be maintained, then, that the state of the "fundamentals" is directly observable. The changing perceptions of the agents can thus result in big fluctuations in expenditure and credit conditions. This article addresses the problems of expectations which can give rise to failures in the coordination of intertemporal plans and consideres policies which could prevent or reduce such upsets; analyses, with regard to fiscal matters, the evaluation by the public sector of its budgetary constraints over time and the possible application of counter-cyclical measures; reviews the alternatives open in terms of the choice of exchange-rate systems in economies with different characteristics (especially the greater or lesser use of foreign currencies as denominators in contracts) and the design of financial policies; briefly refers to the international transmission of macroeconomic impulses, and finally offers some conclusions. 


\section{I}

\section{Introduction}

The recent episodes of great financial volatility and big swings in the level of activity which have been observed in a number of economies have intensified the debate on how major macroeconomic impulses are generated and spread. These phenomena seem to have a special nature, different from that of "small" economic cycles: they cause concern because they can give rise to considerable real costs and they may be associated with discontinuities in the growth path. From the point of view of policy formulation, the experiences of recent years have made economists ask themselves what instruments could serve to make major fluctuations less likely and to improve the "crisis management" measures that might be needed to deal with them. This article seeks to make some contribution to the analysis of these issues.

The analytical approaches taken to study macroeconomic fluctuations marked by credit crises have changed over the course of time. At one time, such fluctuations were considered to be inherent in the evolution of the economic system. Later on, macroeconomic analysis tended to leave them aside, considering them as anomalies that were associated with particular individual economies and were due to visible policy inconsistencies. Recent experience, however, suggests that although there is no reason why such crises should recur systematically, they can affect very different economies and regions and even the international system as a whole.

The events of recent years have had various novel aspects as regards the mechanisms behind the generation of financial disturbances and the patterns of propagation of impulses between economies, al-

$\square$ The author wishes to thank E. Noya, B. Kosacoff and R. Martínez for their valuable comments. A preliminary version of this study was presented in January 1999 at the Eleventh Regional Seminar on Fiscal Policy. The author naturally bears sole responsibility for the views expressed in this article, as well as for any possible errors. though they have also had traditional elements too. ${ }^{1}$ It is generally acknowledged that much remains to be learned about these processes and that it would be useful to explore the lessons that could be drawn from the different experiences in this field. The point of view taken in the present article is that this attitude should be incorporated into the analysis itself, because it has very concrete implications: it is important to bear in mind that the decisions of the economic agents and policy-makers are made in contexts where perceptions and expectations change according to the inferences that each one draws from the evolution of the relevant environment. In these conditions, it is hard to imagine that, in establishing their plans, the actors have a complete and finished model of the working of the economy before them. Something similar occurs in the case of an analyst studying macroeconomic disturbances: in view of the type of phenomenon being studied, the conclusions drawn and the possible recommendations made will necessarily be of a tentative nature.

In the following section (section II), some comments are made on the relation between the fundamental variables and expectations. This question, about which a great deal has been written, is of central importance for interpreting major fluctuations in expenditure and in credit conditions. Section III deals with economic policy issues associated with the prevention and management of major upsets, and finally section IV contains some comments on the international transmission of macroeconomic impulses.

\footnotetext{
${ }^{1}$ Thus, some analogies could be drawn with the "trade crises" of the past, such as those analysed, for example, by Bagehot (1858 and 1873). The existence of such analogies and of questions which have remained unanswered for a very long time shows the complexity of the problems involved in the analysis of such fluctuations. At the same time, the fact that there are examples of crises which have occurred in very different conditions and times would seem to indicate that the fluctuations probably have their origin in general aspects of credit supply and demand decisions rather than in particular details of financial technology, although the latter would of course help to determine the particular features of each episode.
} 


\section{II}

\section{Fundamental variables and expectations}

A sharp distinction is usually drawn between changes in the state of the economy due to movements in the fundamental variables and changes arising from phenomena of coordination of expectations -of the type of self-fulfilling prophecies- in situations with multiple equilibria. It is thus assumed in advance that such variables are objectively definable (subject only to the availability of sufficiently complete and up-to-date information), and it is also assumed that the expectations are always and necessarily consistent with each other, even though the resulting macroeconomic states are not always the best ones compatible with the basic variables.

This distinction is not really as clear as it might seem at first sight, however. When studying the evolution of fiscal policy, for example, the deficit in a given period does not provide sufficient information to determine the sustainability of the government's financial management. It is therefore suggested that indicators should be used which include corrections as a function of the state of the economic cycle or the variation in contingent public sector debts (see ECLAC, 1998a). In order to make such corrections, however, it is necessary to formulate some hypotheses on discrimination between cycles and trends in economic activity or on the size of undocumented public sector commitments, for which purpose it is also necessary to make some conjectures about the future behaviour of the economy. ${ }^{2}$ This point is of a general nature. For example, the interpretation of balance of payments current account results depends on how one assesses such aspects as the growth potential of the economy, the return on the investments being made, or the consistency of consumers' expenditure and indebtedness decisions: in other words, in

\footnotetext{
${ }^{2}$ With regard to the trend-cycle breakdown, it should be borne in mind that the usual filters determine the trend at a particular point in time, using data subsequent to that moment. A recursive estimate, using only information observed up to the current period, may be appreciably different from the "definitive" calculation. This suggests that -for example, when assessing whether a particular form of behaviour has been pro-cyclical or counter-cyclical- a distinction should be made between a retrospective judgement and one based on the knowledge available when the decisions were taken.
}

order to make this interpretation it is necessary to place current behaviour in the context of the expected evolution of the opportunities for generating income (Heymann, 1994). Likewise, the valuation of assets is naturally a function of the perceptions regarding future movements of dividend flows.

Clearly, the fundamental variables do not relate to data at a given moment but to time sequences which must be projected one way or another. Of course, if it is assumed that the processes generating the relevant variables are known, then the projection is automatically formulated on the basis of past observations. In these conditions, "there is nothing new to learn": all the relevant information has already been incorporated in the model on which the expectations are based, and it is known for sure that this model will not be changed, because there are no new inferences to be drawn from the data. The future path of the system would thus be determined by "intrinsically" random disturbances which cannot be represented except in terms of their probability distribution, which is known. ${ }^{3}$

These hypotheses may be a useful approach for a variety of purposes, and it is possible of course that, when dealing with long periods, the past trajectory of an economy can serve for the extrapolation, without too much error, of regularities which have already been incorporated in the schemes of formation of expectations. The validity of such hypotheses is by no means as clear, however, for studying events such as crises, when it is observed that not only are the plans of the agents upset, but also the prior interpretations of the events seem to be generally questioned and there is a feverish search for the "lessons of experience". In other words, these fluctuations

\footnotetext{
${ }^{3}$ It might be useful here to note the distinction, from the point of view of the formation of expectations, between exogenous impulses and those of international origin. The former refer to variables whose evolution is left out of the analysis in the model defining the predictions; the latter include variables due to the actions of agents who do not reside within the economy but, in principle, can nevertheless be represented in order to project the behaviour of the economic environment, just as an individual agent would try to find ways of anticipating the behaviour of other agents with whom he interacts.
} 
seem to correspond to cases of transition in economies whose configuration is changing and in which past patterns of behaviour do not seem to form a sound basis for making predictions. ${ }^{4}$

In situations like these, identification of the fundamental variables ceases to be accurate, both for analysts and for decision-makers. It is not just a question of the greater or lesser availability of data: the lack of accuracy is due to the fact that there is no clearly defined manner of processing the information which will ensure the optimal nature of the expectations generated. In particular, in some cases it is especially difficult to project output and income trends: the changes which take place in the corresponding perceptions as individuals go through their learning processes $^{5}$ can lead to cycles in estimates of wealth and expenditure capacity and in the valuation of assets (Heymann and Sanguinetti, 1998a and b).

When there are no firm bases for projecting future opportunities, decisions and interpretations of observed behaviour are necessarily of a speculative nature, not only because the plans made at a given moment are contingent upon uncertain future events, but also because, for each agent, those plans represent a wager on a particular way of forming expectations, and furthermore their outcome depends on how other individuals make their forecasts and revise them over time. This is also true of economic policy

\footnotetext{
${ }^{4}$ This is a traditional problem: as Walter Bagehot pointed out many years ago, "in many cases crises cannot be attributed beyond reasonable doubt to causes which are known to be real, so that although the problem is clearly visible it is not possible to explain its causes with concrete facts and figures. The circumstances of trade crises differ so much that it is not easy to find a mechanism that can be applied to all of them" (Bagehot, 1858). Some recent studies have acknowledged that, in macroeconomic analysis, it should be borne in mind that data-generating processes can change in an unpredictable manner: as Calvo (1998) points out; "statisticians have the instruments needed to give us an estimate of how shocks are broken down as between permanent and transitory phenomena, but in order to do this it is necessary to make some very strong assumptions, in particular that the present does not differ significantly from the past. However, this assumption is questionable with regard to emerging markets". Moreover, in recent times greater attention has been paid to the statistical properties of series such as those on the returns on assets, which seem to display appreciable discrepancies with the normal distributions, so that a larger proportion of probabilities are at "extreme" values (see, for example, Lo, 1997).

${ }^{5}$ There has been a good deal of discussion in the recent literature about models designed to represent learning processes in economic contexts. See, for example, Sargent (1993), Kirman and Salmon (1995) and Evans and Honkapohja (1998).
}

measures, regardless of the scope of their objectives: in particular, all policies which aim to take account of the government's capacity to generate income over time and the credit conditions it will be facing must also take into account the future evolution of the state of the economy and the perceptions of the various groups of agents. The complexity of public and private decisions is not always obvious, but it becomes very clear at times of crisis.

It may be gathered from the foregoing arguments that, if we accept that there is no sure and universally applicable model for the formation of expectations, then changes in the perceptions about the fundamental variables will play a potentially important role in certain fluctuating circumstances, and such perceptions are a matter of individual opinion. ${ }^{6}$ The formation of expectations will be particularly difficult in periods of transition, when, for example, there are signs of possible speeding-up of income trends which can give rise to upward revisions of investment and consumption opportunities, or when there are fears of an abrupt downward shift. Errors of expectations which have macroeconomic effects will be more frequent in such periods. At the same time, insofar as agents perceive the fragility of their prediction schemes, there will be "flexibility preference" effects: individuals will be reluctant to take positions perceived as being hard to reverse (Hicks, 1974; Dixit and Pindyck, 1994); also, imitative forms of conduct associated with possible "herd behaviour" will begin to assume importance (see Banerjee, 1992).

Reviews of expectations about fundamental variables can thus become a source of macroeconomic fluctuations. A substantial proportion of recent analyses have noted another possibility: that of "self-fulfilling prophecies" in systems that allow of a number of equilibrium paths, whereby the economy can be led to collectively undesirable states, because of the conduct of the other agents, even if each agent

\footnotetext{
${ }^{6}$ From this standpoint, when we refer for example to the "fundamental valuation" of given assets we should perhaps add (even if only implicitly) the awkward phrase "according to the analytical model of the agent making the valuation". This point is of practical relevance. Thus, for example, the concern expressed by the Federal Reserve Board of the United States about share prices (see for example Greenspan, 1997) was connected with doubts about the way assets were valued and, indirectly, doubts about the validity of the growth projections for enterprise earnings underlying the demand for securities.
} 
acts optimally. ${ }^{7}$ Although there can undeniably be interaction among individual expectations, one may wonder about the validity of arguments that attribute crises simply to a (socially) "bad" equilibrium selection. In models on self-fulfilling prophecies, the result is sub-optimal but the individual decisions are fully compatible with each other: all the agents know the path that the system will follow, and act accordingly. There is therefore no doubt about how the economy operates, which contrasts with the marked uncertainty that seems to prevail in such episodes. Quite apart from the foregoing, however, there are queries about how expectations are focussed on a given path and about the options open to economic policy for dealing with situations of self-generated runs, if these are the only disturbing element.

It might be useful to consider a specific case, such as for example a situation where the government has a mass of short-term debt which it has been refinancing. In order to focus on the logic of the argument, let us assume that in the hypothetical economy in question it is common knowledge (i.e., there are well-founded and unanimous expectations, also unanimously seen as such) that the government can service the debt, and has incentives to do so, if it continues to be refinanced. In other words, there are no "fundamental problems" that affect the government's financial position. There will thus be a good equilibrium in which each asset-holder, anticipating that all the others will be willing to keep on lending, will consider that the best policy for him is to do the same and buy bonds once again when they mature. Consequently, there are no disturbances and no inducement for policy changes. If the level of indebtedness is sufficiently high, however, there may also be another type of equilibrium in which the collective expectation is that the creditors will refuse to refinance the debt; ${ }^{8}$ if there is a stampede the

\footnotetext{
${ }^{7}$ With regard to matters such as the generation of bank runs and the refinancing of the public debt, see for example Calvo, 1988, and Sachs, Tornell and Velasco, 1996. Diamond and Dybvig (1983), for their part, present a bank run model and analyse policy issues connected with those mentioned in the following paragraph of this article.

${ }^{8}$ Determining the probability to be assigned to the different possible states is a delicate matter in arguments on multiple equilibria. Here, in order to simplify the argument, it is assumed that the possibility of a panic was not incorporated in the predictions, although this is close to being a contradiction if it is desired to represent the expectations of the agents as
}

government will not be able to generate the resources to rescue the debt, so that its obligations will be paid off at a discount (either explicitly, or through a rise in prices, if the debt is in local currency), thus confirming the initial pessimistic forecasts. In this case, there is a self-fulfilling prophecy of a policy turnaround which is entirely the result of the formation of expectations, since such a turnaround would not occur in the case of the other possible equilibrium.

Obviously, the costs assumed by the agents in the bad equilibrium could potentially be avoided: what is needed is to coordinate decisions properly. In the foregoing example, the government does in principle have the means to do this. If, in the event of signs of a stampede, it decides to pay off the maturing bonds with other securities offering similar yields, then everything would take place (according to the hypotheses of this exercise) as if the government had persuaded asset-holders to "select the right equilibrium", thus bringing the system to an optimum state. In this situation, there is no need for a fiscal adjustment, or discounting of the debt, or upward leaps in price levels, because there is no fundamental reason calling for this. At the same time, from the standpoint of the private agents, although the refinancing of the debt would force each of them to carry out an action which would be different from that which they would have chosen in the stampede equilibrium, it would not cause losses: ${ }^{9}$ on the contrary, according to the assumptions of the example, this measure would lead to a state which was preferable for all the individuals in question (or at least no worse) compared with the situation that would exist if such a measure were not taken. In the hypothetical

rational. At all events, the respective probabilities perceived by individuals could depend in turn on the predictions regarding the economic policy responses in terms of the coordination of expectations (see the analysis of this matter later on in this article).

${ }^{9}$ This conclusion is a consequence of the hypotheses of the example, which ignore the possibility that some agents might assign great importance to the fact of having immediate availability of their funds (for example, if they had planned to concentrate their expenditure on the moment of maturity of the assets and they had no other possibilities of gaining access to liquid resources). At all events, the argument is not substantially modified by the incorporation of this effect if it can be assumed that the number of agents in this situation is known approximately, even though there is no information allowing them to be individually identified (see Diamond and Dybvig, 1983). 
case of the exercise, there would therefore be no reason why the refinancing should cause loss of prestige by the government.

The foregoing analysis seems to suggest that if a crisis occurs as the result of self-fulfilling prophecies, this could be because the government does not act (although capable of doing so) in a manner which serves to coordinate the agents' plans in the direction of a better state in which the predictions are also fulfilled. If the idea that crises can be prevented relatively easily seems at first sight rather implausible, this is not due to a flaw in the argument as such but to the hypotheses on which it is based, especially the assumption that the attack on certain assets could take place even in the absence of any uncertainty over the fundamental values determining the debtors' creditworthiness. In practice, expectation coordination phenomena often seem to take on importance precisely when there are doubts over repayment capacity (for example, it is hard to imagine a run on deposits if there are no indications of problems in the banks' portfolios). This does not mean, of course, that the assessments of repayment capacity are necessarily homogeneous and correct. On the other hand, "liquidity crises" can have powerful real effects by forcing the liquidation of assets and a contraction in credit (see Kiyotaki and Moore, 1997), which has repercussions in turn on the wealth of the agents and hence their creditworthiness.

Various types of financial crises which have repercussions on real activity may be distinguished (see Calvo, 1995, and Leijonhufvud, 1998). In the case of the phenomena of interest to us (associated with events such as the Latin American crises of the early 1980 s or the more recent macroeconomic upsets in Asia and Latin America), there have been big changes in perceptions of the creditworthiness of the public sector or major segments of the private sector, as well as sharp oscillations in the supply of credit and the capacity to finance the demand for goods. A feature shared by various cases is that they displayed big movements in the estimations of wealth, reflected in expenditure decisions and the valuation of assets. It is also clear that fluctuations are amplified and spread through variations in the severity of liquidity constraints. In other words, in these cases the effects originating in changes in the forecasts about the fundamental variables, in contagion of expectations and in fluctuations in liquidity conditions mingle in such a way that they confront private agents and policy makers with complex challenges as regards the identification of signals and the taking of decisions. The following section focuses on matters relating to economic policy management.

\section{III}

\section{Economic policy responses to major disturbances}

In the view of the foregoing analysis, credit crises can be associated with downward revisions of the wealth perceptions of macroeconomically significant agents, the effects of which spread through secondary impacts on income and wealth and the tightening of liquidity constraints. In these episodes, many agents must suffer losses and reduce expenditure in order to adapt to their intertemporal budgetary restrictions. It is possible, however, that there may be over-adjustments due to the excessive volatility of expectations and illiquidity effects. In cases of major disturbances, amplification mechanisms probably enter into action which multiply the cost of the original disturbance. From the standpoint of policy manage- ment, it is important that the necessary adjustments should be made, but it is also important that unnecessary contractions should be avoided. Crises are periods of great uncertainty in which it is by no means a simple matter to determine the sustainable levels of income and expenditure of economic units and groups of agents. In these conditions, policy decisions can hardly be approached on the basis of mechanical criteria, without taking into account the state of the economy and the public sector's capacity for action. These difficulties highlight the value of safeguard measures.

The management of economic policy over time raises various queries about the incentives that guide 
decisions at given moments and the way in which policy design incorporates the possibility that "unexpected" circumstances may arise and determines the action that should be taken when this happens. The comments made in this section will deal primarily with the latter type of questions. It is clear from the start that any idea of defining strategies that are optimal for any set of contingencies is not realistic. This would be tantamount to trying to programme generic actions in advance, which would call for unattainable levels of knowledge on the operation of the system and the shocks that could occur over time. Consequently, if we acknowledge the difficulty of identifying rigorously fixed criteria which do not admit any exceptions, ${ }^{10}$ what we must do is to seek approaches that take account of the learning process effected in analytical work and the observation of concrete experience. Furthermore, the problem of the prevention and management of major disturbances has special features, since it concerns phenomena whose probability and specific details cannot be accurately known in advance, because they are relatively infrequent and are usually associated with more or less rapid changes in the configuration of the economies in question. This particularly affects the assessment of the costs and benefits of preventive measures: quite apart from the "subjective" nature of the attitudes towards risks it is difficult to define with numerical precision probability distributions of events of different types and intensities that could serve as the basis for more precise calculations. At all events, in recent times we have seen that there is a by no means negligible potential for macroeconomic instability, and economic policies should naturally be formulated in the light of this fact.

\footnotetext{
${ }^{10}$ Once again, this is a traditional issue in macroeconomic discussions. Thus, when commenting on proposals to add an "elastic clause" to the monetary system of his time (that is to say, an "escape clause" that would add a pre-specified contingent element to the prevailing rules), Bagehot (1858) takes the view that "the essential principle is that at a certain point in trade crises the directors of the bank and/or the government should be empowered to authorize an additional issue of banknotes, suitably backed by securities". He considers that the need for such a faculty can hardly be questioned, although there are many great difficulties in determining exactly how it should be granted. In contrast, he considered that the "elastic clause" seemed a more artificial expedient, concluding that the whole matter was a question of "choosing between different types of difficulties".
}

\section{Fiscal policy}

It is a well known fact that disorder in the public finances involves heavy economic costs. When the public sector is unable to handle the demands for expenditure within the constraints imposed by its capacity to generate resources, it lacks the means to define systematic policies. High and changing rates of inflation, possibly interrupted by occasional but transitory attempts at stabilization, are a typical symptom of such situations. Quite apart from the distortions that the inflation tax generates in itself, inconsistency in fiscal matters generates instability in policies too, since the government is forced to act as a function of the pressures of the moment. The resulting volatility complicates decisions and narrows the agents' horizon for planning ahead. The consequences are clearly visible in economic performance, especially in the credit markets, because the parties to a possible contract cannot predict their future situation except in the short term. This further heightens the liquidity constraints, not only for the government but also for broad groups of private agents. In order to overcome these situations, it is essential to take measures to restore the creditworthiness of the public sector.

As already noted, creditworthiness is a prospective notion. At all events, experience suggests that perceptions of the soundness of the government finances over time gradually change as a function of its observed behaviour: a history of instability can affect the public sector's access to credit for a long time. Especially in the case of economies which are facing a change in their fiscal system, there will probably be some tension between the incentive to give signals of financial soundness and the search for areas of action that can help soften macroeconomic impacts.

In analysing fiscal policy as a macroeconomic instrument, it is impossible to leave out the situation of the public sector and the state of the economy. It may be said that the considerable changes that have taken place in views on the role of such policy are partly due to the fact that the typical cases to which the analyses refer have been changing. In studies written after the 1930s depression, emphasis was placed on the counter-cyclical effect that such policy could have on aggregate demand and the desirability of easing fiscal policy in recessions. The argument was that the creditworthiness of the public sector was not in question (so that the government would have 
no difficulty in financing possible deficits, which the public would see as transitory phenomena) and there were situations of insufficient effective demand in which it was difficult for the private sector to coordinate a level of expansion which would lead to "normal" use of the available resources. Now, however, many proposals take a markedly different attitude: that there is no reason why fiscal policy should seek to affect the level of activity and that, in any case, the best contribution it could make in this sense is to avoid a situation where public indebtedness exerts pressure on the credit markets: in the event of an adverse shock priority should be given to adjusting policies to maintain a low public deficit.

In view of these clear discrepancies, it might be useful to imagine two extreme situations resulting from a shock which reduces activity. In the first, possible suppliers of credit perceive the government as being in a fragile creditworthiness position. In this scenario, it is assumed that these perceptions are highly influenced by the short-term evolution of fiscal policy, either because it is expected that the disturbance will have lasting effects on public sector income or because creditors appraise the fiscal attitude of the government as a function of its immediate behaviour. Any attempt to issue new debt would hence raise growing doubts about repayment possibilities. Not only would the harder credit conditions affect the public sector but the uncertainty over fiscal policy would also affect the private sector's capacity to finance expenditure. In any event, the budgetary constraints on the government would be such as to make fiscal adjustment the only option (which does not mean that it would not also be costly), unless the government resorted to the even more costly expedient of inflation. In the second situation, aggregate expenditure is reduced for some reason and doubts arise about the solvency of a significant part of the private sector; the recession spreads through the hardening of credit conditions and the fall in employment. If the government is seen as being creditworthy, the "flight to quality" in the demand for assets may possibly increase the propensity of individuals who have funds to hold public securities. In these circumstances, a large number of agents will be facing serious liquidity constraints and, at the same time, the government can take out debt at a low cost. Thus, expansionary fiscal policy operations would be possible which, by increasing the resources available to the agents suffering from a shortage of liquidity, would help to secure a recovery in aggregate demand and thus improve the opportunities of individuals as a whole ${ }^{11}$ (Leijonhufvud, 1973).

This argument is applicable to cases of pronounced contraction, and differs from the traditional analyses as regards the management of fiscal policy over time on the basis of "representative agent" constructs (Lucas, 1986). There are also some general points of contact, however: a form of fiscal management which seeks to improve the possibilities for agents managing production and consumption over time should be based on an appraisal of the type and persistence of the shocks observed. This means examining projections of the future conditions of the economy. There is also a certain similarity between the two cases referred to in the previous paragraph. In the first case, the liquidity problems primarily affect the public sector; in the second, they affect a large group of private agents: what is needed is to channel resources from the less constrained sector to the more constrained sector, through an adjustment which reduces the deficit, or through measures which increase the spending capacity of the illiquid units, as appropriate. One thing is clear: in order for the government to be able to embark on this latter type of fiscal operations designed to soften the impact of the disturbances on the private sector, it must have a sound level of creditworthiness.

In practice, the government's scope for action depends on the state of the economy. Major disturbances in aggregate expenditure and the level of production not only affect the capacity to collect taxes but can also abruptly increase the public debt, explicitly or not (rescue operations for the financial system are a typical example of this). This means that, even from the restricted standpoint of looking after the public finances, it is important to limit the size of recessions. On the other hand, however, it is possible

\footnotetext{
${ }^{11}$ It is well known that when there are liquidity constraints, the Ricardian equivalence proposition does not hold; that is, these operations would be effective even when there is a clear perception that the increased public debt will generate a rise in future taxes. It should be noted that in a situation like that described here there are big differences between the implicit discount rates of different individuals: one group possesses liquid resources and is willing to lend at a low rate if there is no risk, but finds it difficult to identify creditworthy potential debtors, while the other group has a strong preference for current expenditure, since its opportunities are limited by current income, which is comparatively low. Thus, the action of fiscal policy may be equated with that of establishing a financial intermediation channel between the two groups.
} 
that situations may arise where strong restrictions on private sector activity may be combined with difficult access to credit on the part of the government, if the latter is unable to make it clear that it can make up for present deficits with greater generation of funds in the future. Such cases raise particularly complex problems of fiscal policy decision-making because of the combination of opposing demands: complying with the budgetary constraints and preserving what is left of public credit, avoiding an over-adjustment in the provision of services, softening the impact on private expenditure and probably also taking care of distributive tensions, which may increase.

The possibility that conditions of this type may arise highlights the importance of preventive measures. There is general consensus on the desirability of practising counter-cyclical fiscal management. Maintaining a certain amount of leeway in the public finances when the economy is operating normally is particularly useful when the possibility that the private sector could be a source of instability is not completely ruled out. Such leeway can take various specific forms, such as the accumulation of liquid funds (or the implementation of contingent financing mechanisms which make it easier to gain access to funds when needed), but at all events it would appear to require a degree of "taxation capacity" previously unused in periods of expansion which could serve as backing for credit if some event which has an impact on the economy occurs. As is usually the case with insurance mechanisms, preventive policies are not without their costs, but the dangers involved in fiscal fragility have been amply demonstrated. At the same time, however, the idea that fiscal management should include elements to protect against the possibility of negative shocks still leaves open the question of how to identify trends in the evolution of the economy: one form of caution in this respect could be to avoid over-hasty extrapolation into the future of signs of strong growth ${ }^{12}$ and to take action if it is seen that the private sector is taking decisions on the basis of exaggerated projections.

12 In this respect, mention may be made of Talvi's argument (Talvi, 1996) on the interpretation of the fiscal results in the case of the demand booms which usually accompany some stabilization programmes: the problem here is confusion of a sudden transitory rise in revenue with a permanent one, the difficulty being that it is not easy to distinguish between the two kinds of shocks in transitional periods.

\section{Financial policies and exchange rate regimes}

The debate on financial policies leaves little room for simplistic positions. It is difficult to give general validity either to the arguments that the public sector can and should control the assets markets in detail or to those that assume that, in the absence of distorting interventions, those markets have self-regulating properties which automatically guarantee their proper overall functioning. Obviously, credit conditions sometimes show great instability, and in such cases economic policy should take action in one way or another: there are a number of examples of large-scale interventions (with heavy fiscal costs) which contradicted previous announcements that the government would not interfere (Vaz, 1999). At the same time, however, identifying mechanisms that will ease the smooth evolution of financial transactions and reduce instability is no simple matter, not only because of the analytical complexity of the problem but also because the configuration of financial systems changes, as well as differing from one country to another. The range of contracts (as regards the variety of assets, terms and denominations) and the forms of intermediation seem to depend on the past history of the economy. Although it is useful to seek criteria that can be applied more or less generally, these specific features need to be taken into account.

These special characteristics become clear when one considers the links between the credit markets and the exchange rate regime. At one extreme, there are the cases where a large part of the assets issued by residents of a country are in the hands of other residents and the instruments are mostly denominated in local currency; when the agents display a demand for liquidity they are likewise showing a propensity to increase their local currency holdings. This means, on the one hand, that if there are massive withdrawals of funds from the financial system and the public sector is called upon to act as lender of last resort, a currency issue will not always immediately lead to pressures on the foreign exchange market if the increase in the money supply is matched by greater demand. Likewise, movements in the external parity of the currency need not necessarily have a substantial effect on the willingness to offer credit, because asset-holders consider above all the purchasing power of their positions in terms of domestic goods: as long as domestic inflation does not change too much, fluctuations in the exchange 
rate do not have much effect on individuals' perceptions of their wealth or expectations regarding debt service capacity, although they do change relative prices and the incentives for different types of activity.

At the other extreme, there is the case of a highly dollarized economy, where the liquidity reserves consist mainly of foreign exchange and financial contracts are mostly denominated in foreign currency. Here, in particular, a fall in the willingness to keep funds in the banks when there are doubts about the soundness of those entities is quickly reflected in greater demand for external assets and the government is thus induced to provide those assets in one form or another if it wishes to avoid a situation where the financial system ceases to fulfill its foreign currency commitments (when the effects of the shock on the exchange rate are so serious that the withdrawals of foreign currency deposits cannot be made good with the corresponding liquid assets of the intermediaries), preventing the shift of the local currency deposit portfolio to liquid foreign exchange. In an economy of this type, an exchange rate devaluation automatically leads to a revaluation of liabilities and operates as a debt deflation mechanism of the type described by Fisher (1933): it thus has wealth effects and can in itself bring on a contraction in credit, by bringing into question the solvency of borrowers (and probably also by rendering more uncertain the real value of payments for contracts using the denominator previously applied by convention). Thus, in these circumstances it is very likely that a devaluation will help to spark off or heighten a recession. The dollarization of credit acts as a strong disincentive against allowing major movements in the exchange rate.

There is of course a wide range of intermediate cases between the two extremes in question. ${ }^{13}$ How-

\footnotetext{
13 This variety concerns not only the relative proportions of financial contracts denominated in local or foreign currency but also the use of schemes such as price indexing, which is often applied in some countries (and is usually associated with a history of inflation which is persistent but does not reach extreme levels). From the point of view of our analysis, indexed contracts are quite a different matter from those denominated in foreign currency, since the real value of the payments does not depend directly on variations in the exchange rate. Indeed, a sudden rise in the exchange rate would tend to reduce the real value of indexed debts (in so far as it is associated with a rise in domestic inflation, and bearing in mind that the price indexes currently applied have lags), whereas it would increase the real value of commitments expressed in foreign currency (if domestic prices vary less than proportionately).
}

ever, it may be noted that attitudes to variations in the exchange rate differ according to the economy in question: in some cases governments go to great lengths to limit the size of exchange rate swings, whereas in others they give priority to other criteria. At this point, it is worth considering why exchange rate flexibility can be useful. Limited fluctuation of the exchange rate can introduce a certain amount of friction into capital movements and give monetary policy some degree of autonomy; at the same time, the price of foreign exchange acts as an adjustment mechanism for relatively small disturbances. The main question, however, is what the response to very strong disturbances should be: i.e., if it is acceptable to allow the exchange rate to register a correspondingly large variation. When this is not so (either because of the characteristics of the financial system or because it is considered that exchange rate stability and price stability are closely associated), ${ }^{14}$ it seems reasonable that the exchange rate regime should try to reduce uncertainty about the possibility of a major devaluation; keeping the option open would then mean paying a certain price (especially in terms of high interest rates, with the corresponding problems for public and private debtors) in order to maintain a degree of flexibility that there would be little inclination to use when the time came. On the other hand, if the reaction of the market to exchange rate uncertainty is to make wider use of foreign currency in contracts, then this -as already noted- tends to make it more difficult to use the exchange rate as a means of adjustment. It is also clear, however, that rigidity entails its own costs, which become particularly evident when there are disturbances of external origin. The dilemmas that arise in choosing exchange rate systems emphasize the fact that there is no simple regime which is definitely preferable to the other alternatives, whatever the characteristics of the economy.

\footnotetext{
${ }^{14}$ The analysis made here has laid stress on the disturbances in the system of financial contracts that can be caused by big variations in the exchange rate in economies where many debts are expressed in foreign currency. Past experience (including that of recent episodes) suggests that abrupt devaluations are generally associated with considerable rises in the real exchange rate: this means that there is not an equally sharp response by domestic prices. Even so, in some cases the exchange rate is the main nominal anchor; this feature can also be linked with the ways contracts are denominated.
} 
The dollarization of financial assets can of course be induced by economic policy measures, but it can also occur more or less spontaneously. Within the limits of the influence of economic policy, there may be options which are by no means unimportant: the spread of the use of foreign currency as a unit of account in financial operations restricts monetary management in a manner which it may be difficult to reverse, but in some conditions it seems to be almost essential in order to endow the credit markets with a certain density, especially in the case of transactions which are not of a very short-term nature. These conditions may also be associated with attitudes on the part of the public which require that capital movements with the exterior should be smooth and easy if assets are to be kept in the country.

It is quite natural that the variability of international flows of funds should have given rise to discussions about the treatment that should be given to different forms of movement of resources (Agosin and Ffrench-Davis, 1997; UNCTAD, 1998). It is worth bearing in mind, in this respect, that (except in conditions of strict rationing) the volume of external finance is not an externally given quantity but is determined in conjunction with the decisions on production and expenditure, and therefore depends on the expectations and behaviour of the agents in the economy itself. Nevertheless, great fluctuations have been observed in the supply of credit from the central countries to the rest of the world, and these oscillations have had similar effects in very different economies. Changes in the opportunities for access to international credit have undoubtedly become macroeconomic impulses of prime importance -just as important as variations in the terms of international trade, if not more so- ${ }^{15}$ and in a variety of cases they have given rise to abrupt changes in the rates of real expenditure and production. Such instability causes problems. What is less clear is how far it is possible to reduce the transmission of externally made valuations to the yields on domestic assets: in economies which are already integrated into the international capital market it would seem difficult to generate frictions that could avoid cases of arbitrage outside very limited ranges and thus prevent major

15 On the other hand, these two types of impacts can well be linked: the effects of a fall in export prices can be amplified by a contraction in the supply of finance. shifts in international interest rates or the risk perceptions of external operators from being reflected in local markets.

Capital movements take the form of changes of ownership of different types of assets. A widespread source of concern is the possibility that there may be rapid reversals of short-term capital flows which force a sudden contraction in expenditure if creditors demand that their loans be paid off. The concentration of finance in short-term instruments is undoubtedly an element of fragility, since there are generally no matching resources rapidly available for servicing debts. Apart from the normal activity of changing maturities carried out by the financial system, it is only reasonable that public or private agents should try to avoid major discrepancies between the time-patterns of their income and obligations. Here too, however, dilemmas can arise. At times of uncertainty, suppliers of credit will probably show a preference for flexibility, and this will lead to big differences in yields, depending on the length of the loan. In these circumstances, a rise in long-term interest rates is in itself an impulse favouring a contraction in aggregate demand. At the same time, the fact that debtors prefer to obtain longer-term loans does not give any indication of what spread they would be willing to pay. ${ }^{16}$ At the limit, if the cost of long-term indebtedness becomes prohibitive, the stark choice may be between accepting shorter maturities on liabilities or reducing expenditure immediately. The first of these choices means wagering that credit conditions will ease in the future if the reigning uncertainty is dispelled, which may or may not occur; at all events, the fragility produced by a concentration of short-term debt is probably the effect of some problem (reversible or not, depending on the circumstances) of perceptions of creditworthiness. In many cases, strategies based on the idea of gaining time may end up in a collapse (due to the refusal of creditors to keep on refinancing the debt), but this depends on the specific circumstances, so that it is difficult to formulate a general proposition.

\footnotetext{
${ }^{16}$ At this point, the indeterminate nature of the probabilities of different situations becomes important if there are multiple equilibria, because if these probabilities are not known it is not possible to define accurately the value, for the recipient of a loan, of "insurance" against the possibility that his creditors will decide not to refinance the loan and will demand the return of their funds.
} 
Similar dilemmas may appear in other areas, especially in the interaction between financial and exchange rate policies. It is not unusual for episodes in which there is a break with a fixed exchange rate regime to be associated with bank crises (Kaminsky and Reinhart, 1996). There is clearly a relation between the two phenomena: when banks begin to have liquidity problems, there will probably be a conflict between the need to act as a lender of last resort and the maintenance of enough international reserves to back up the exchange rate. It is hard to imagine the central bank (or the public sector as a whole) remaining on the sidelines if there is uncertainty about the repayment of deposits in the banking system. ${ }^{17}$ But an expansion in the money supply to help the banks involves the risk of increasing the demand for foreign exchange, and raising interest rates in order to maintain the level of the reserves may aggravate the situation of debtors. Here too, policy management in the face of these dilemmas (which also involve fiscal management) seems to call both for a judgement on the nature of the shock and for various types of conjectures: how far has loss of confidence spread through the system as a whole?, is there an irreversible deterioration in portfolio quality, and is this limited to only a few firms or not?, how much access do the banks have to foreign funds?, what prospects does the government have of obtaining external resources?, how will the demand for money respond to an increase in official credit to the banks? and so forth. In order to size up the situation in these conditions it is necessary to collect and process information, but above all to formulate a general view on the basis of the available indicators, although the time available for deciding on actions is very limited (and the planning horizon of the private agents is shortened too): by their very nature, crises raise very complex decision-making problems.

A first element for reducing the probability of acute crises is to recognize that, although their frequency and intensity cannot be determined precisely,

${ }^{17}$ And an announcement by the authorities that they will refrain from taking action may have only a very limited effect on exchange rate credibility, because the collapse of the banks will very likely have repercussions on the public finances, either directly, if the government finally covers the losses incurred once the problem has worsened, or indirectly, through a fall in aggregate activity: it is an example of "unpleasant arithmetic" (Sargent and Wallace, 1981), involving a temporarily contractive monetary policy to deal with a probable deterioration of the fiscal position. major disturbances in the assets markets do occur from time to time, and economies are particularly likely to suffer them if they are very sensitive to international conditions or are undergoing changes in their configuration which can give rise to potentially volatile expectations. This recognition will naturally lead to more or less continuous activity in the detection of signs of problems. ${ }^{18}$ This point applies in particular to the banking system. There is no need to stress the importance of supervision and of the application of prudential regulations on capital inflows, liquidity and the way to treat credit risks, which reduce the system's exposure to aggregate impulses and forestall faulty management of the institutions in question and the generation of serious moral hazard problems (Rojas-Suárez and Weisbrod, 1996; De Juan, 1996). Experience shows that shortcomings of supervision appreciably increase the fragility of the banking system (and, ultimately, can give rise to heavy contingent debts for the government) and, conversely, that the strengthening of prudential control mechanisms puts the economy in a better position to absorb shocks.

Likewise, if the government incorporates in its decisions the possibility that it may, in certain emergency situations, be obliged to provide liquidity assistance to the financial sector or to face situations of volatile demand for money, as well as recognizing that exchange rate instability can entail high costs, it will be advisable for it to maintain a relatively high volume of readily available reserves (as a proportion, for example, of bank liabilities not covered by their own liquid foreign exchange holdings). Obviously, in order to build up these funds in conditions of price stability it will be necessary to generate present or future fiscal surpluses (or at least not use the resources from seigniorage for expenditure if the demand for money increases) and to freeze assets that could be used for other purposes. At the same time, the availability of resources for use in emergencies

\footnotetext{
18 Apart from the importance of looking for signs that will give early warning of disturbances, it will probably be difficult to identify reliable advance indicators in general terms, precisely because the problem is to predict sharp reversals of expectations, and this does not appear to permit the use of purely mechanical procedures.
} 
provides a means of giving greater credibility to the financial and exchange system and provides some flexibility of action for softening the impact of fluctuations in the asset markets: accumulating funds does involve costs, but on the other hand the existence of such funds allows policy measures to moderate interest rate rises when there is a contraction of credit and at the same time reduces the risk that the exchange rate may be destabilized.

Nevertheless, it seems unlikely that it would be possible to define regulations which, without imposing excessively strict limits on intermediation operations (and hence without excessively restricting credit to those units which rely on the banks for their finance, typically small enterprises), at the same time reduce the likelihood of systemic problems in the banks to the minimum. This means that there will not be "full-coverage insurance". Furthermore, experience shows that volatility of securities values can also give rise to considerable fluctuations in credit conditions. Likewise, regardless of whether the public sector has built up reserves as a preventive measure or not, it is possible that the economy may be faced with such serious conditions of illiquidity that its capacity for policy intervention on the basis of the assets at its direct disposal is exceeded. The episodes of recent years have shown that, one way or another, international emergency finance has played an appreciable role in efforts to moderate the effects of shocks on various economies. Both for this reason and because of the interdependencies which exist between different economies, we will now analyse the question of possible international arrangements to deal with episodes of very strong turbulence.

\section{The international transmission of impulses}

There are various types of channels for the international transmission of macroeconomic impulses. In addition to the traditional mechanisms (through trade operations and market conditions in the financial centres), in recent times special attention has been paid to the effects of common movements in the asset prices of different countries. These effects can themselves be due to different causes, such as:

i) changes in the international economy which are reflected in a similar manner in several countries;

ii) direct impacts of some economies on others (through trade, for example), which are incorporated into the perceptions on asset yields; iii) perceived analogies in the configurations or policies of countries, which cause certain agents to interpret some events in one economy as being useful for predicting the behaviour of others; this mechanism would appear to operate in a context of learning about the fundamental variables, through information perceived as being capable of being extended to other cases which individuals extract (rightly or wrongly, in retrospective) from the evolution of different economies;

iv) spillover effects, because the liquidity constraints of operators specializing in holding securities of a group of countries would cause them, in the event of falls in the prices of some securities, to sell off other assets ${ }^{19}$ (Calvo, 1998); this would have effects that could be amplified by cases of "herd behaviour" on the part of other agents who base their decisions on the observed actions of the first group, ${ }^{20}$ either because they think they reflect useful information (Banerjee, 1992) or because they are applying "follow the market" strategies due to principal-agent problems $^{21}$ (Krugman, 1998);

v) possible "self-fulfilling prophecy" phenomena sparked off by certain events which act as focal points for the coordination of expectations.

\footnotetext{
${ }^{19}$ It should be noted that this argument calls for some particular hypotheses in order to rationalize strong contagion effects: one of these hypotheses is that such specialists (who would have more information than that possessed by the average operators in the market about conditions in the respective economies) have a portfolio that contains debt of different countries at the same time. A proposition resulting from this argument (although there is no clear evidence that this has been observed in practice in recent episodes) is that specialists who have few holdings of securities of the country which set off the downward movement in prices, or who do not suffer from liquidity constraints, should simultaneously increase their demand for debt of the other countries and thus moderate the severity of the contagion.

${ }^{20}$ It is worth recalling that information cascades -in which agents imitate the actions of the others instead of relying on direct first-hand information- are more likely when the information the agents possess themselves is considered unreliable. The appearance of such effects would thus seem to indicate a pre-existing state of uncertainty.

21 This refers to the fact that portfolio managers may be evaluated by their clients by comparison with the evolution of the market average, thus making them reluctant to take positions that are much different from "general opinion".
} 
There are some indications that in critical episodes there is increased correlation between the demand for assets of different countries. ${ }^{22}$ However, it is hard to distinguish the effects of the different mechanisms that could have operated in each case, and still harder to determine the importance of such mechanisms in possible future cases. Furthermore, although certain indicators of fragility may be useful, it is not clear what specific conditions make an economy more vulnerable to contagion. Thus, from a prospective point of view, the question is posed in very general terms: there are sometimes states of great uncertainty in which the effects of the international transmission of financial disturbances are heightened and are added to the spread of impulses through trade.

It is well known that the existence of international spillovers can give rise to demands for the coordination of macroeconomic policies. At the same time, crisis situations usually compromise as a whole the macroeconomic instruments of countries and therefore typically reduce the degree of freedom for determining the "coordination supply" (Heymann and Navajas, 1992). Recent experience is instructive in this respect: in the countries directly affected by disturbances there was no sign of significant activity for the joint determination of macroeconomic measures. Instead, there were "emergency" mechanisms for the provision of liquidity, defined by the central countries and international loan agencies with the aim of reducing the impacts on the various countries and inhibiting the spread of the upsets to other countries. At all events, the criteria and procedures behind these interventions continue to be the subject of heated debate.

When analysing possible international-scale macroeconomic action it is necessary to bear in mind the great variety of actors involved: the residents of the individual countries, in their roles as economic agents and participants in domestic politics; the operators on the international financial markets; the authorities who define policies in each country; regional coalitions, whether of a lasting or temporary nature, and the relevant international institutions. In circumstances like these, in which multiple agents with different interests, relative weights and possibly different perceptions interact with each other, the

22 See, for example, Calvo and Reinhart (1996) and Eichengreen, Rose and Wyplosz (1996). "game" that gives rise to decisions is by no means simple. Nevertheless, there are some basic features which are obvious even at a cursory glance.

A first point which is obvious but nevertheless worthy of note is that the behaviour of the central economies has strong external repercussions: the evolution of the economic cycle, of exchange parities and of credit conditions in those economies acutely influences the opportunities of other regions. The policies of the central economies are naturally decided as a function of domestic considerations; there is little coordination among them, and the impacts on third countries, if taken into account at all, are only considered in critical situations, when widespread, large-scale upsets are observed that could affect them. Obviously, differences of size give rise to differences in behaviour, and these are a fundamental given element of the problem. However, it seems important to acknowledge the international effects of policies and to establish arrangements whereby at least the countries or regions that receive the impact of impulses can participate by transmitting and receiving information on the future prospects of the economies and policy lines. Arrangements for interaction are by no means an insignificant element in decision-making, even though they may not take the form of explicit commitments. They are also important in so far as it is sought to prevent international-scale disturbances and to establish guidelines on action to deal with them if they do occur, because although big macroeconomic swings occur in an occasional manner it would be desirable to follow up the evolution of the international economy more or less continuously, with the participation of policy-makers (ECLAC, 1998b; Ocampo, 1999).

The set of emergency financing measures applied in recent episodes implicitly recognize the fact that, in certain circumstances, the possibility of handling crises goes beyond the national level. These episodes have given rise to a debate on the desirability of establishing some more formal mechanism for acting as an international lender of last resort. Defining systems of this type is undoubtedly a difficult matter. There are, of course, moral hazard problems, both for the lenders and the recipients of the funds. However, the cost of the crises for the debtor countries has generally been high (even when they have received emergency credits to bolster up their liquidity), so that it is hard to see what incentives there could be for them to engage in policies which volun- 
tarily increase the likelihood of an adverse shock. Moreover, since it is generally considered very important to maintain easy access to international markets, possible opportunistic forms of behaviour would probably be limited by considerations of reputation. At the same time, the discretionality inherent in the function of lender of last resort could become a source of conflicts if this function were carried out by an international agency; something similar would apply in the case of the functions of supervision of financial systems associated with that role.

These arguments (quite apart from the uncertainty about the size of the funds that might be needed in different circumstances and the difficulties involved in making advance commitments to contribute resources, if the latter were very large) would suggest that credit aid to economies facing crises should be maintained as a possibility to be decided when the case arises. Such occasional schemes also present problems, however, especially as regards the timeliness of the measures (which would tend to be taken only when the crisis was clearly acute), the criteria on the availability and use of the resources, and the definition of the conditions applicable to such aid. Here, once again, there are dilemmas and trade-offs. It would seem possible to devise mechanisms defining the basic criteria (such as those on fiscal performance and the supervision arrangements applied by countries to their financial systems) regarding the requirements that an economy must fulfill in order to have access to contingency finance in the event of disturbances in credit facilities (see for example Agosin, 1999). Such criteria would necessarily be rather arbitrary when the time came to apply them, and their announcement could amplify the fluctuations in some cases, but they would nevertheless provide an element of predictability and would possibly facilitate the operation of counter-cyclical

\footnotetext{
23 What would be desirable (although undoubtedly hard to do in practice) would be to help to identify impacts of a transitory nature and cases where the upsets are not due to previous departures from "good" policies, so that prudence in times of expansion would be rewarded by greater capacity to keep up the level of activity in crises. In this respect, credit risk ratings have given rise to heated debate because of their possible pro-cyclical effect (ECLAC, 1998b).
}

policies, especially to deal with signs of contraction. $^{23}$

The regulation of credit markets has an international aspect: the financial fragility of some economies has repercussions on others, and the rules laid down by the central countries undoubtedly affect the conditions of access to resources for the rest of the world. This justifies the attempts to define international standards (not necessarily identical for countries with different characteristics, or fixed over time). At the same time, although it is natural that there should be concern over the volatility of the supply of credit for the emerging countries and its effects in terms of amplifying and spreading fluctuations, there might be a danger that, if there were strict regulations in the central countries, these could operate as a sort of tax on the export of resources which might affect the amount and cost of credit for countries requiring finance.

In some groups of countries, a substantial part of their trade in goods is with neighbouring countries in their region but financial transactions are mainly with the centres. This is so in the case of Mercosur (although the geographical concentration of trade varies between the countries). In such conditions, it seems useful to analyse possible policy coordination exercises, not in a "self-contained" context (where only the regional participants are actors) but bearing in mind the effect that the behaviour of each economy has on the interaction (especially in financial matters) of the others with the rest of the world. In order for a number of countries to agree to engage in the coordinated management of their macroeconomic instruments, the perceived incentives must be very strong. There must therefore not only be close economic interdependence but also previous experience in forms of coordination which do not restrict the decisions of the parties too much: at all events, concerted policy definition is always a gradual process. The macroeconomic spillover is also more intense if there is a regional component in the supply of finance to each economy, however. Quite apart from the usefulness of mechanisms for consultation and the exchange of information, it may also be beneficial to define some regional guidelines of a macroeconomic nature (whether or not in the form of explicit commitments) aimed at reducing uncertainty about the mutual impacts between the economies. 


\section{IV}

\section{Final comments}

Decisions on saving, investment and asset holdings depend on expectations which vary with changes in perceptions and forms of analysis. These changes sometimes cause major shifts in the perceived opportunities of the agents, especially when doubts set in about the creditworthiness of debtors. It is difficult to define the likelihood of major disturbances accurately; the mechanisms behind the spread of impulses in these cases also seem complex. It would be dangerous, however, to ignore the potential volatility of the supply and demand of credit, especially when one bears in mind that economies are constantly evolving, so that the patterns of behaviour observed in the past are of only limited validity for judging how agents make their forecasts.
A basic responsibility of economic policy is not to become a factor of instability itself; at the same time, it should act to forestall and moderate serious macroeconomic fluctuations. In order to do this, the public sector must keep itself financially sound and use its leeway for action to cope with critical situations. Even so, it is likely that in certain circumstances the magnitude of impacts and their transmission from one economy to another will make it essential to take measures that go beyond the national level. Linking up policies to forestall and deal with crises at the national, regional and international level raises by no means negligible problems of design and implementation.

(Original: Spanish)

\section{Bibliography}

Agosin, M. (1999): Towards a New Architecture for the International Financial System: Lessons from the Financial Crisis, Santiago, Chile, University of Chile, Centro de Economía Internacional y Desarrollo.

Agosin, M. and R. Ffrench-Davis (1997): Managing capital inflows in Chile, Santiago, Chile, University of Chile, Facultad de Ciencias Económicas y Administrativas.

Bagehot, W. (1858): The monetary crisis of 1857 , in N. St. John-Stevas (ed.), The Collected Works of Walter Bagehot, vol. X, London, The Economist, 1974.

(1873): Lombard Street, in N. St. John-Stevas (ed.), The Collected Works of Walter Bagehot, vol. IX, London, The Economist, 1974.

Banerjee, A. (1992): A simple model of herd behavior, Quarterly Journal of Economics, vol. CVII, No. 3, Cambridge, Massachusetts, MIT Press.

Calvo, G. (1988): Servicing the public debt: The role of expectations, American Economic Review, vol. 78, No. 4, Nashville, Tennessee, American Economic Association.

(1995): Varieties of Capital Market Crises, Working Paper No. 306, Washington, D.C., Inter-American Development Bank (IDB).
(1998): Contagion and sudden stops, Baltimore, Maryland, University of Maryland, mimeo.

Calvo, G. and C. Reinhart (1996): Capital Flows to Latin America: Is there Evidence of Contagion Effects?, Policy research working paper No. 1619, Washington, D.C., World Bank.

De Juan, A. (1996): The roots of banking crises: Microeconomic issues and supervision and regulation, in R. Haussmann and L. Rojas-Suarez (eds.), Banking Crises in Latin America, Washington, D.C, IDB.

Diamond, D. and P. Dybvig (1983): Bank runs, deposit insurance and liquidity, Journal of Political Economy, vol. 91, No. 3, Chicago, Illinois, The University of Chicago Press.

Dixit, A. and R. Pindyck (1994): Investment under Uncertainty, Princeton, New Jersey, Princeton University Press.

ECLAC (Economic Commission for Latin America and the Caribbean) (1998a): The Fiscal Covenant: Strengths, Weaknesses, Challenges, LC/G.1997/ Rev.1, Santiago, Chile.

(1998b): The International Financial Crisis: An ECLAC Perspective, LC/G.2040, Santiago, Chile. 
Eichengreen, B., A. Rose and C. Wyplosz (1996): Contagious currency crises: First test, in T. Andersen and K. Moene (eds.), Financial Liberalization and Macroeconomic Stability, Oxford, U.K., Basil Blackwell.

Evans, G. and S. Honkapohja (1998): Learning dynamics, Eugene, Oregon, University of Oregon, mimeo.

Fisher, I. (1933): The debt-deflation theory of great depressions, Econometrica, vol. 1, Evanston, Illinois, The Econometric Society.

Greenspan, A. (1997): Statement to the US Congress, Washington, D.C., 27 February.

Heymann, D. (1994): Sobre la interpretación de la cuenta corriente, Desarrollo Económico, vol. 34, No. 135, Buenos Aires, Instituto de Desarrollo Económico y Social (IDES).

Heymann, D. and F. Navajas (1992): Coordinación de políticas macroeconómicas: aspectos conceptuales vinculados con el Mercosur, Documento de trabajo $\mathrm{N}^{\circ} 45$, Buenos Aires, ECLAC Office at Buenos Aires.

Heymann, D. and P. Sanguinetti (1998a): Business cycles from misperceived trends, Economic Notes, vol. 27, No. 2, Siena, Italy.

(1998b): Quiebres de tendencia, expectativas y fluctuaciones económicas, Desarrollo Económico, vol. 38, No. 149, Buenos Aires, IDES.

Hicks, J. (1974): The Crisis of Keynesian Economics, Oxford, U.K., Oxford University Press.

Kaminsky, G. and C. Reinhart (1996): The twin crises: the causes of banking and balance of payments problems, Washington, D.C., mimeo.

Kirman, A. and M. Salmon (1995): Learning and Rationality in Macroeconomics, Oxford, U.K., Basil Blackwell.

Kiyotaki, N. and J. Moore (1997): Credit cycles, Journal of Political Economy, vol. 105, No. 2, Chicago, Illinois, The University of Chicago Press.

Krugman, P. (1998): Currency crises, Cambridge, Massachusetts, mimeo.
Leijonhufvud, A. (1973): Effective demand failures, in A. Leijonhufvud, Information and Coordination, Oxford, U.K., Oxford University Press, 1981.

(1998): Two types of crises, Zagreb Journal of Economics, vol. 2, No. 2, Zagreb, Croatia.

Lo, A. (1997): Fat tails, long memory and the stock market since the 1960s, Economic Notes, vol. 26, No. 2, Siena, Italy.

Lucas, R. (1986): Principles of fiscal and monetary policy, Journal of Monetary Economics, vol. 17, No. 1, Amsterdam, Netherlands, North-Holland Publishing Company.

Ocampo, J. A. (1999): Reforming the International Financial Architecture: Consensus and Divergence, "Temas de coyuntura" series, No. 1, Santiago, Chile, ECLAC.

Rojas-Suarez, L. and S. Weisbrod (1996): Banking Crises in Latin America: Experiences and Issues, Working paper series, No. 321, Washington, D.C., IDB.

Sachs, J., A. Tornell and A. Velasco (1996): The Mexican peso crisis: Sudden death or death foretold?, Journal of International Economics, vol. 41, No. 3/4, Amsterdam, Netherlands, North-Holland Publishing Company.

Sargent, T. (1993): Bounded Rationality in Macroeconomics, Oxford, U.K., Clarendon Press.

Sargent, T. and N. Wallace (1981): Some unpleasant monetarist arithmetic, Federal Reserve Bank of Minneapolis Quarterly Review, Minneapolis, Federal Reserve Bank of Minneapolis, winter.

Talvi (1996): Exchange Rate-Based Stabilization with Endogenous Fiscal Response, Working paper series, No. 324, Washington, D.C., IDB.

UNCTAD (United Nations Conference on Trade and Development) (1998): Trade and Development Report 1998, United Nations, New York and Geneva.

Vaz, D. (1999): Four banking crises. Their causes and consequences, Revista de Economía, vol. 6, No. 1, Montevideo, Banco Central del Uruguay. 